\title{
Chromosome alterations in human hepatocellular carcinomas correlate with aetiology and histological grade - results of an explorative $\mathrm{CGH}$ meta-analysis
}

\author{
P Moinzadeh ${ }^{1,4}$, K Breuhahn*,1,4,5, H Stützer ${ }^{2}$ and P Schirmacher 1,3,5 \\ 'Institute of Pathology, Joseph-Stelzmann Str. 9, University of Cologne, 5093 I Cologne, Germany; ${ }^{2}$ Institute of Medical Statistics, Informations and \\ Epidemiology, University of Cologne, 5093 I Cologne, Germany; ${ }^{3}$ Center for Molecular Medicine, University of Cologne, Joseph-Stelzmann Str. 9, 50931 \\ Cologne, Germany
}

\begin{abstract}
All available comparative genomic hybridisation (CGH) analyses $(n=31$, until 12/2003) of human hepatocellular carcinomas (HCCs; $n=785)$ and premalignant dysplastic nodules (DNs; $n=30)$ were compiled and correlated with clinical and histological parameters. The most prominent amplifications of genomic material were present in Iq (57.1\%), 8q (46.6\%), 6p (22.3\%), and 17q (22.2\%), while losses were most prevalent in 8p (38\%), I6q (35.9\%), 4q (34.3\%), I7p (32.1\%), and I 3q (26.2\%). Deletions of 4q, 16q, I3q, and 8p positively correlated with hepatitis B virus aetiology, while losses of $8 p$ were more frequently found in hepatitis $C$ virus-negative cases. In poorly differentiated HCCs, I3q and $4 \mathrm{q}$ were significantly under-represented. Moreover, gains of Iq were positively correlated with the occurrence of all other high-frequency alterations in HCCs. In DNs, amplifications were most frequently present in Iq and $8 q$, while deletions occurred in 8p, 17p, 5p, 13q, 14q, and 16q. In conclusion, aetiology and dedifferentiation correlate with specific genomic alterations in human HCCs. Gains of I q appear to be rather early events that may predispose to further chromosomal abnormalities. Thus, explorative CGH meta-analysis generates novel and testable hypotheses regarding the cause and functional significance of genomic alterations in human HCCs.
\end{abstract}

British Journal of Cancer (2005) 92, 935-94I. doi: I0.1038/sj.bjc.6602448 www.bjcancer.com

Published online I March 2005

(c) 2005 Cancer Research UK

Keywords: hepatocellular carcinoma; hepatocarcinogenesis; hepatitis-B virus; hepatitis-C virus; comparative genomic hybridisation; meta-analysis

Hepatocellular carcinoma (HCC) is one of the most prevalent cancers with steadily increasing incidence even in developed countries, such as Europe and the United States (El-Serag, 2002). It is believed that human hepatocarcinogenesis persists several decades normally starting from chronic liver disease over cirrhosis, premalignant precursor lesions (dysplastic nodules (DNs), 'early' HCC upto fully malignant HCC with angioinvasive and metastatic potential (reviewed in Kern et al, 2002a). In more than $80 \%$ of the cases, a well-defined aetiology (e.g. viral infection, aflatoxin B1 exposure, and chronic alcohol abuse) is associated with the development of HCC. Hepatitis B virus (HBV) infection is thought to contribute by two different mechanisms to hepatocarcinogenesis: chromosomal integrations of viral DNA with destabilising effects for the host genome (Luber et al, 1996) and

\footnotetext{
* Correspondence: Dr K Breuhahn, Institut für Pathologie, University of Heidelberg, Im Neuenheimer Feld 220/221, 69120 Heidelberg, Germany; E-mail: kai.breuhahn@med.uni-heidelberg.de

${ }^{4}$ These authors contributed equally to this work

${ }^{5}$ Current address: Institute of Pathology, University of Heidelberg, Im Neuenheimer Feld 220/221, 69120 Heidelberg, Germany

Received 21 October 2004; revised 13 December 2004; accepted 12 January 2005; published online I March 2005
}

expression of viral transactivating factors ( $\mathrm{HBxAg}$ and preS/SAg; Kekule et al, 1990; Koike, 1995). The oncogenic potential of hepatitis $\mathrm{C}$ virus (HCV) infection has been linked to the viral transcriptional activator NS5A (Kato et al, 1997) and also to the core polypeptide (Moriya et al, 1998). Moreover, tumorigenic properties of aflatoxin $\mathrm{B} 1$ are linked to somatic $\mathrm{G} / \mathrm{T}$ transversion in codon 249 of TP53 (Ozturk, 1999). Furthermore, several cellular factors have been implicated in the pathogenesis of HCC (e.g., TP53 (p53; Feitelson, 1998), CTNNB1 ( $\beta$-catenin; Prange et al, 2003), RB1 (retinoblastoma; Zhang et al, 1994), COX2 (cyclooxygenase-2; Kern et al, 2002b), IGF2 (insulin-like growth factor-II; Breuhahn et al, 2004), and CDH1 (E-cadherin; Matsumura et al, 2001)).

Studies of the overall chromosomal alterations in carcinomas are based on loss of heterozygosity (LOH) analyses and comparative genomic hybridisation (CGH). Comparative genomic hybridization is a fluorescence-based technique that is used for the detection of chromosomal imbalances in tissues or cell populations. Areas representing loss of genomic material may contain tumour suppressor genes, while gains may harbour dominant protumorigenic factors (e.g. oncogenes and growth factors) relevant for respective tumour entity. The power of CGH lies in its potential for a more or less unbiased whole genome screening; the main limitation is its relatively low resolution. By CGH several chromosomal regions carrying tumour-relevant genes 
(e.g. oncogenes) have been identified in solid tumours and haematological malignancies (reviewed in Weiss et al, 2002).

However, many information regarding relevant chromosomal rearrangements that may play a central role in the development of HCC are still missing. Meanwhile, over 30 different in part small CGH studies have generated a wealth of over 700 analysed HCCs that await comprehensive and comprising interpretation. The aim of this study was to compile the information from all available CGH data of human DNs/HCCs and to correlate these alterations with aetiology and histological grading. The results demonstrate a significant association of specific genomic imbalances with viral aetiology and histological grade, and generate further testable hypotheses.

\section{MATERIALS AND METHODS}

\section{Comparative genomic hybridisation-studies}

Overall, 785 different CGH analyses of HCCs are available from 31 studies (public NCBI database PubMed; published until 12/2003; see Supplementary online material). Inclusion criteria for the CGH studies were complete data profiles and explicit tumour classification (HCC, DN) as well as similar software and labelling systems and used thresholds $(0.7-0.8$ and $1.2-1.3)$. Information regarding the HBV status was present in 428 cases (244 HBV-positive and 184 HBV-negative cases). The HCV status was available in 338 cases (110 HCV-positive and $228 \mathrm{HCV}$-negative cases).

Tumour grading was given in 199 cases (126 cases with low grade $(\mathrm{G} 1 / 2)$ and 73 cases with high-grade (G3/4) HCCs). Overall $30 \mathrm{CGH}$ analyses of DNs were collected from four different studies (see Supplementary online material).

\section{Data recording and statistical analyses}

All CGH data were recorded in a standardised fashion: each chromosome arm was divided from 0 to 100 (centromere to telomere direction) and gains, losses, or normal ratio were evaluated in steps of five. From these data, the respective charts and ideograms were displayed. Moreover, the data were submitted to statistical analyses using SPSS. However, when only parts of a chromosomal arm were affected, it was scored as a complete loss of the arm in the summarising tables. When specific chromosomal aberrations occurred in $20 \%$ of all analysed cases, they were rated to be high frequency. These aberrations were specifically submitted to further examination. Statistical evaluation was performed using explorative $\chi^{2}$ test. $P$-values cited were not corrected for multiple testing. The list of known tumour relevant genes localised in the chromosomal regions with imbalances of highest frequency was determined using the OMIN database (Online Mendelian Inheritance of Man).

\section{RESULTS}

\section{Predominant chromosomal alterations in human HCCs}

The complete meta-analysis of all available CGH data $(n=785$ HCCs) revealed that gains of chromosomal material were most prevalent in $1 \mathrm{q}(57.1 \%$ of the cases), $8 \mathrm{q}(46.6 \%), 6 \mathrm{p}(22.3 \%)$, and $17 \mathrm{q}(22.2 \%)$, and losses were most frequently present in $8 \mathrm{p}(38 \%)$, $16 \mathrm{q}(35.9 \%), 4 \mathrm{q}(34.3 \%), 17 \mathrm{p}(32.1 \%)$, and 13q (26.2\%) (Table 1). These data testify amplifications and deletions of chromosomal arms on which oncogenes (e.g. MYC on 8q24) and tumour suppressor genes (e.g. $R B 1$ on 13q14) are located. Furthermore, several genes with known and potential protumorigenic functions (e.g. modulators of the WNT-signalling pathway like FZD3, WISP1, $S I A H-1$, and AXIN2) have been described to be grouped on respective chromosomal arms (Table 1).

\section{Hepatocellular carcinoma aetiology correlates with specific genomic imbalances}

In $428 \mathrm{CGH}$ analyses of HCCs, the HBV status was given (244 HBV-positive and $184 \mathrm{HBV}$-negative cases). When HBV-positive

Table I Frequencies of chromosomal alterations in human HCCs

\begin{tabular}{|c|c|c|c|c|c|c|c|c|}
\hline \multirow[b]{2}{*}{ Chromosome } & \multicolumn{4}{|c|}{ p-arm } & \multicolumn{4}{|c|}{ q-arm } \\
\hline & Loss (\%) & Gain (\%) & High. Fre. & Genes $^{c}$ & Loss $(\%)^{a}$ & Gain (\%) & High. fre. & Genes $^{c}$ \\
\hline । & 15.4 & 5.2 & - & - & 0.6 & 57.1 & q2I.I-q44 & WNTI 4, FASL \\
\hline 2 & 1.4 & 7.1 & - & - & 2.9 & 8 & - & - \\
\hline 3 & 3.9 & 5 & - & - & 1.9 & 8.8 & - & - \\
\hline 4 & 10.6 & 6 & - & - & 34.3 & 1.7 & $q 21.1-q 35$ & LEFI, CCNA \\
\hline 5 & 1.7 & 13.6 & - & - & 7.8 & 11.1 & - & - \\
\hline 6 & । & 22.3 & - & $P I M I, C D K N I A$ & 15 & 7.9 & - & - \\
\hline 7 & 0.9 & 15 & - & - & 3.1 & 16.8 & - & - \\
\hline 8 & 38 & 4.6 & p21.1-p22 & FZD3, PLK3 & 1.9 & 46.6 & $q 22.1-q 24.3$ & MYC, WISPI \\
\hline 9 & 14 & 3.3 & - & - & 11.1 & 2.9 & -1 & - \\
\hline 10 & 2.7 & 8.3 & - & - & 11.1 & 4.1 & - & - \\
\hline | | & 5.4 & 4.3 & - & - & 10.2 & 9.4 & - & - \\
\hline 12 & 6.5 & 2.4 & - & - & 2.9 & 6.9 & - & - \\
\hline 13 & 0 & 0 & - & - & 26.2 & 7.4 & $q 14.1-q 22$ & $R B I, B R C A 3$ \\
\hline 14 & 0 & 0 & - & - & 11.3 & 4.1 & - & - \\
\hline 15 & 0 & 0 & - & - & 5.4 & 4.6 & - & - \\
\hline 16 & 16.8 & 3.4 & - & - & 35.9 & 1.8 & $q 12.1-q 24$ & $\mathrm{SIAHI}, \mathrm{CDHI}$ \\
\hline 17 & 32.1 & 2.9 & pl3 & p53, HICl & 3.7 & 22.2 & $q 23-q 25$ & AXIN2, TIMP2 \\
\hline 18 & 4.1 & 5.5 & - & - & 10.8 & 5 & - & - \\
\hline 19 & 6.9 & 5 & - & - & 3.8 & 10.4 & - & - \\
\hline 20 & 2 & 14.9 & - & - & 0.9 & 18.6 & - & - \\
\hline 21 & 0 & 0 & - & - & 8.8 & 2.2 & - & - \\
\hline 22 & 0 & 0 & - & - & 6.4 & 2.8 & - & - \\
\hline$x$ & 5 & 11.2 & - & - & 4.5 & 15 & - & - \\
\hline Y & 5.1 & 2.3 & - & - & 5.6 & 2.3 & - & - \\
\hline
\end{tabular}

${ }^{\mathrm{a}}$ Frequencies $\geqslant 20 \%$ are highlighted in bold. ${ }^{\mathrm{b}}$ Regions with highest frequency of imbalances on the respective chromosomal arm are highlighted in bold. ${ }^{\mathrm{C}}$ Examples of known tumour-relevant genes located on the respective chromosomal high-frequency region. 


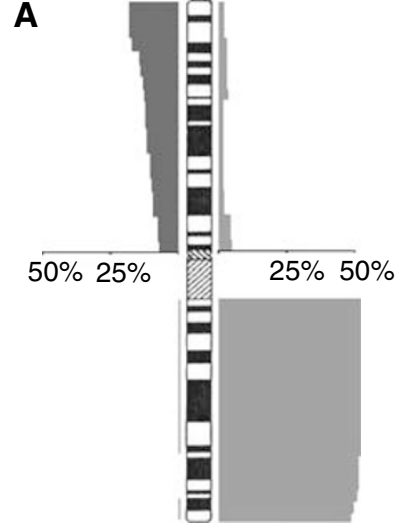

Chr. 1; HBV-positive

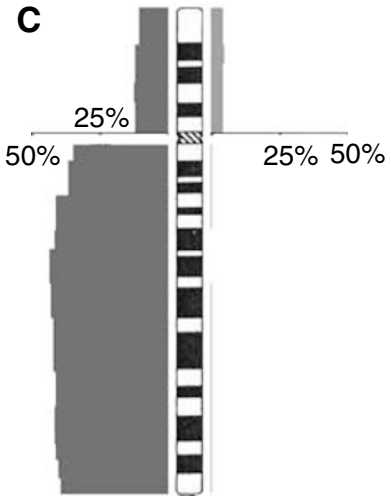

Chr. 4; HBV-positive

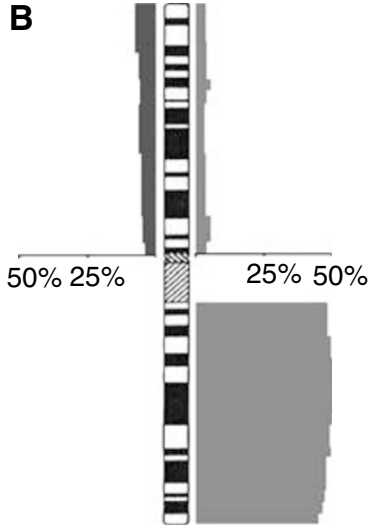

Chr. 1; HBV-negative

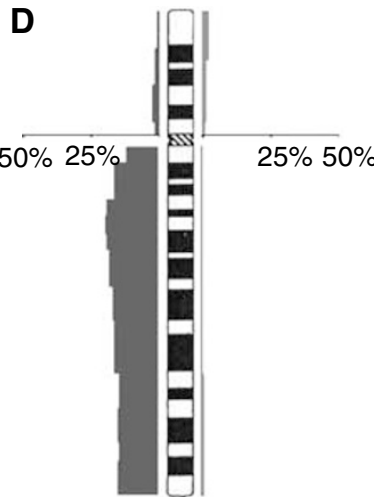

Chr. 4; HBV-negative
Figure I Distribution of genomic imbalances $(n=428)$ with regard to HBV aetiology (for details, see Table 2). Data are exemplarily demonstrated for chromosomes I (no differences between $(\mathbf{A})$ HBV-positive and (B) HBV-negative HCCs) and four (significant difference between (C) HBV-positive and (D) HBV-negative HCCs).

and -negative cases were compared, losses at $4 \mathrm{q}(43.4$ vs $19.6 \%)$, $16 \mathrm{q}(41.8$ vs $18.5 \%), 13 \mathrm{q}$ (31.1 vs $19.6 \%)$, and $8 \mathrm{p}$ (40.6 vs $29.3 \%)$ were positively correlated with $\mathrm{HBV}$ aetiology (Figures 1 and 2; Table 2). The 338 HCCs with known HCV status consisted of 110 HCV-positive and $228 \mathrm{HCV}$-negative cases. Among these cases, only losses of $8 \mathrm{p}$ were more frequent in $\mathrm{HCV}$-negative cases (36 vs $20 \%$ ) (Figure 2; Table 2). No other significant association of genomic imbalances in HCCs with viral infections was found (data not shown).

\section{Histological grade of HCCs correlates with genomic imbalances}

Next we analysed whether the histological grade (tumour differentiation) of the HCCs correlated with the observed pattern of chromosomal aberrations (Table 3). In 199 cases the histological grade was specified (126 low-grade (G1/G2) and 73 high-grade (G3/G4) HCCs). Losses of $13 \mathrm{q}$ (43.8 vs $11.9 \%)$ and $4 \mathrm{q}(45.2$ vs $23 \%)$ were significantly more frequent in high-grade HCCs while the other high-frequency genomic imbalances did not correlate with the tumour grade (data not shown).

\section{Correlations between different genomic imbalances}

We next tested whether any of the high-frequency imbalances $(\geqslant 20 \%)$ were statistically connected. Altogether, 498 CGH analyses of HCCs given as individual profiles were accessible to

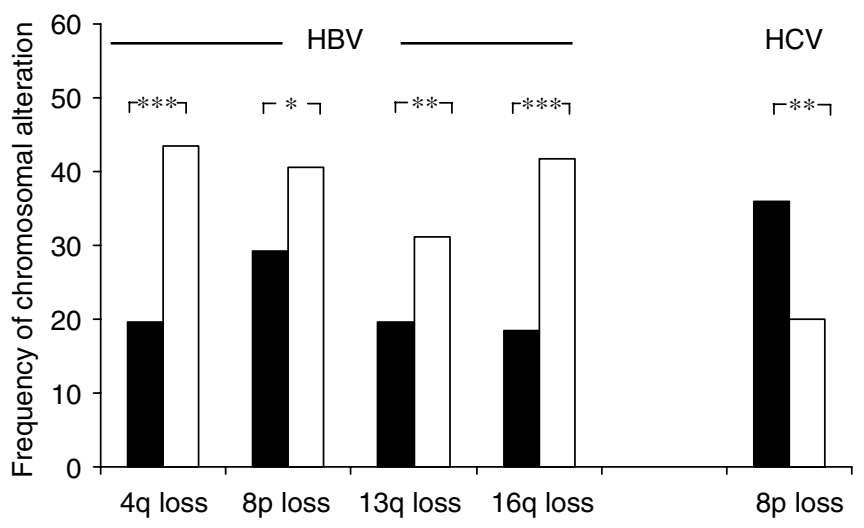

Figure 2 Graphical comparison of significant high-frequency genomic alterations in HBV- or HCV-negative (black bars) and HBV- or HCVpositive human HCCs (white bars). $* P<0.05$; $* * P<0.0$ I; **** $P<0.001$.

this analysis. Deletions of genomic material on $4 \mathrm{q}, 13 \mathrm{q}$, and $16 \mathrm{q}$ frequently coincided. Furthermore, gains of $1 \mathrm{q}$ were positively associated with all other high-frequency alterations, except gains on chromosome 17q (Table 4).

Hepatocellular carcinomas with gains on 1q $(n=293 ; 58.8 \%)$ were compared to cases without genomic alterations of $1 \mathrm{q}$ $(n=205 ; 41.2 \%)$ regarding the occurrence of additional chromosomal imbalances per case. A significantly higher number of chromosomal imbalances were found in HCCs with 1q gains $(6.74$ imbalances per case) than in HCCs without 1q gains (3.40 imbalances per case; $P<0.05)$.

\section{Genomic macroimbalances in human DNs}

Four different studies have analysed a limited number of DNs $(n=30)$ by CGH. Altogether, DNs showed genomic imbalances, although at a lower frequency as compared to HCCs. Gains were detectable in $1 \mathrm{q}(30 \%)$ and $8 \mathrm{q}(10 \%)$, while losses were most prevalent at $8 \mathrm{p}(16.7 \%), 17 \mathrm{p}(16.7 \%), 5 \mathrm{p}, 13 \mathrm{q}, 14 \mathrm{q}$, and 16q (all $10 \%$ ); (Figure 3 ). In DNs only gains on $1 \mathrm{q}$ were frequently detectable in more than $20 \%$ of all analysed cases.

\section{DISCUSSION}

This meta-analysis of CGH data of human HCCs has unravelled several correlations between aetiology as well as histological grade and genomic imbalances. However, this analysis is afflicted with several restrictions as a result of not identical criteria in different studies.

(a) Aetiology: Some well-established reasons for human HCCs, such as chronic alcoholic liver disease, genetic haemochromatosis, and aflatoxin B1 exposure, are either ill defined and/ or have not been evaluated in a sufficient number of cases studied by CGH. Therefore, we restricted our analysis to the potential associations with the HBV and HCV status. Analyses of the viral status carried some inconsistency by itself. Especially, in most studies HBV aetiology was evaluated by assaying for HBsAg in the serum. In contrast, HBV may exhibit its protumorigenic effects despite HBV seroconversion (Paterlini and Brechot, 1991). Significant correlations of chromosomal rearrangements with HBV aetiology have been unravelled, but in our analysis they may have been even more pronounced, if complete HBV serology would have been performed in all studies.

(b) Lack of a uniform histological grading: Several grading schemes are in use for HCC (Edmondson and Steiner, 1954), and in many studies it remains unclear which grading scheme 
Table 2 Comparison of significant high-frequency genomic imbalances ( $\geqslant 20 \%$; see Table I) in human HCCs with HBV- $(n=428)$ and HCV-aetiology $(n=338)$

\begin{tabular}{|c|c|c|c|c|c|c|}
\hline \multirow[b]{2}{*}{ Chromosome } & \multicolumn{3}{|c|}{ HBV $^{*}$} & \multicolumn{3}{|c|}{ HCV* $^{*}$} \\
\hline & Negative $(n=184)$ & & Positive $(n=244)$ & Negative $(n=228)$ & & Positive $(n=110)$ \\
\hline 4q (loss; \%) & 19.6 & $P<0.0005$ & 43.4 & 26.3 & $P=0.896$ & 27.3 \\
\hline 6p (gain; \%) & 21.2 & $P=0.488$ & 24.2 & 24.1 & $P=0.121$ & 16.4 \\
\hline 8q (gain; \%) & 37.0 & $P=0.05$ & 46.7 & 42.1 & $P=0.194$ & 34.5 \\
\hline I3q (loss; \%) & 19.6 & $P=0.008$ & 31.1 & 28.5 & $P=0.363$ & 23.6 \\
\hline 16q (loss; \%) & 18.5 & $P<0.0005$ & 41.8 & 28.1 & $P=0.898$ & 27.3 \\
\hline
\end{tabular}

*Significant differences are highlighted in bold $(P<0.05)$.

Table 3 Comparison of significant high-frequency genomic imbalances $(\geqslant 20 \%$; see Table I) in human HCCs with regard to tumour grade ( $n=199$; low grade: $\mathrm{G}$ I and $\mathrm{G} 2$ tumours; high grade: $\mathrm{G} 3$ and $\mathrm{G} 4$ tumours)

\begin{tabular}{lccc}
\hline & \multicolumn{3}{c}{ Tumour grade $^{*}$} \\
\cline { 2 - 4 } Chromosome & Low (G I+G2) & & High (G3+G4) \\
\hline Iq (gain; \%) & 54.0 & $P=0.459$ & 60.3 \\
4q (loss; \%) & $\mathbf{2 3 . 0}$ & $\mathbf{P}=\mathbf{0 . 0 0 1}$ & $\mathbf{4 5 . 2}$ \\
6p (gain; \%) & 19.8 & $P=1.0$ & 19.2 \\
8p (loss; \%) & 32.5 & $P=0.876$ & 34.2 \\
8q (gain; \%) & 39.7 & $P=0.299$ & 47.9 \\
I3q (loss; \%) & $\mathbf{1 1 . 9}$ & $\mathbf{P}<\mathbf{0 . 0 0 0 I}$ & $\mathbf{4 3 . 8}$ \\
I6q (loss; \%) & 23.8 & $P=0.053$ & 37.0 \\
I7p (loss; \%) & 33.3 & $P=0.443$ & 39.7 \\
I7q (gain; \%) & 19.8 & $P=0.224$ & 27.4 \\
\hline
\end{tabular}

*Significant differences are highlighted in bold $(P<0.05)$.

has been applied. Due to this fact and in order to generate groups large enough for statistical analysis, it was necessary to combine grades 1 and 2 (well differentiated) and 3 and 4 (poorly differentiated), which is in accordance which numerous studies in other carcinomas.

Despite these restrictions, a number of high-frequency genomic imbalances have been clearly identified (Figure 1). With some of these aberrations the expression of tumour relevant genes may be correlated, such as RB1 (13q), CDH1 (16q), SIAH1 (16q), and TP53 (17p). Interestingly, some of these genes have been described to participate in pivotal signalling pathways frequently dysregulated in HCCs (reviewed in Ozturk, 1999). While the p53 protein is involved in different cellular processes (e.g. apoptosis, cell cycle, and differentiation; Levine, 1997), dysregulation of retinoblastoma protein ( $R B 1), \mathrm{p} 21^{\mathrm{WAF}}(C D K N 1 A)$, and CyclinA2 (CCNA) directly regulate initiation and progression of DNA synthesis (Zhang et al, 1994; Qin et al, 1998). Notably, several components of the WNTsignalling pathway were localised on aberrant genomic regions (WNT14, LEF1, FZD3, WISP1, SIAH-1, and AXIN2). This is of particular interest since upto $40 \%$ of all HCCs exhibit nuclear enrichment of $\beta$-catenin, the transcriptional activator of the WNT pathway (Cui et al, 2003; Prange et al, 2003). However, higher resolution techniques, such as matrix-CGH (Wessendorf et al, 2002) and expression analyses, will have to verify the expected expression changes for most genes.

Losses of $4 \mathrm{q}, 13 \mathrm{q}, 16 \mathrm{q}$, and $8 \mathrm{p}$ were significantly correlated with HBV aetiology. Although the responsible genes are currently unknown, HBV-related chromosomal rearrangements have been mapped to 4q (Blanquet et al, 1988; Pasquinelli et al, 1988; Buetow et al, 1989). This suggests that in addition to well-established HBVassociated oncogenic mechanisms such as transcriptional transactivation by viral proteins (Wollersheim et al, 1988; Caselmann et al, 1990; Kekule et al, 1990) and nonhomologous chromosomal integration of viral DNA (Nagaya et al, 1987), specific corresponding host factors involving tumour suppressor genes positioned at the respective chromosomal loci may exist. Identification of these responsible genes may generate further insight into the mechanisms of HBV-induced oncogenesis.

Although the number of analysed premalignant lesions (DNs) is still low, several conclusions can already been drawn: Significant genomic imbalances can be detected in DNs and they partly resemble the changes present in HCCs, although at a lower frequency. This further supports the current hypothesis that DNs are indeed the immediate premalignant precursors of HCCs.

Another important question is the time point at which the different genomic imbalances occur during the process of hepatocarcinogenesis. Gains of $1 \mathrm{q}$ are the most frequent alteration in DNs and appear at equal frequencies in well and poorly differentiated HCCs; this suggests that amplifications of $1 \mathrm{q}$ represent an early protumorigenic change that mostly precedes malignant transformation. In contrast, deletions of $4 \mathrm{q}$ and $13 \mathrm{q}$ are found significantly more frequent in poorly differentiated HCCs. This suggests that both alterations are late progression events that typically occur after malignant transformation.

Statistical analyses demonstrate that $1 \mathrm{q}$ gains are positively correlated with all other high-frequency alterations, suggesting that 
Table 4 Correlation analysis of genomic aberrations in human HCCs (in $\geqslant 20 \% ; n=498$ )

\begin{tabular}{|c|c|c|c|c|c|c|c|c|c|}
\hline Chromosome & Iq (gain) & 4q (loss) & 6p (gain) & 8p (loss) & 8q (gain) & I3q (loss) & 16q (loss) & I7p (loss) & 17q (gain) \\
\hline \multicolumn{10}{|l|}{$\mathrm{lq}$} \\
\hline gain & - & 43 & 30.6 & 45.7 & 52.6 & 30.2 & 38.1 & 36.8 & - \\
\hline$\varnothing$ & - & 19.8 & 11.1 & 25.6 & 30.4 & 16.4 & 23.7 & 21.3 & - \\
\hline \multicolumn{10}{|l|}{$4 q$} \\
\hline Loss & 73.4 & - & - & 51.6 & - & 42 & 53.2 & 41 & 29.8 \\
\hline$\varnothing$ & 41.9 & - & - & 28.7 & - & 13.9 & 19.4 & 23.9 & 15.5 \\
\hline \multicolumn{10}{|l|}{$6 p$} \\
\hline Gain & 76.9 & - & - & 52.1 & - & - & - & - & - \\
\hline$\varnothing$ & 45.9 & - & - & 32.6 & - & - & - & - & - \\
\hline \multicolumn{10}{|l|}{$8 p$} \\
\hline Loss & 66.3 & 46.6 & 33.7 & - & - & - & 48.3 & 41 & - \\
\hline$\varnothing$ & 46.6 & 26.3 & 17.2 & - & - & - & 23.1 & 24.4 & - \\
\hline \multicolumn{10}{|l|}{$8 q$} \\
\hline Loss & 68.7 & 57.3 & - & - & - & - & 52.7 & - & - \\
\hline$\varnothing$ & 48.2 & 25.3 & - & - & - & - & 24.8 & - & - \\
\hline \multicolumn{10}{|l|}{$16 q$} \\
\hline Loss & 65 & 56.4 & - & 55.2 & - & 41.1 & - & 42.9 & - \\
\hline$\varnothing$ & 47.8 & 22.4 & - & 28.7 & - & 16.4 & - & 24.2 & - \\
\hline \multicolumn{10}{|l|}{$17 p$} \\
\hline Loss & 66.9 & 44.8 & - & 51.3 & - & - & 46.8 & - & - \\
\hline$\varnothing$ & 48.8 & 28.5 & - & 31.1 & - & - & 25.6 & - & - \\
\hline \multicolumn{10}{|l|}{$17 q$} \\
\hline Gain & - & 55 & - & - & - & - & - & - & - \\
\hline$\varnothing$ & - & 28.2 & - & - & - & - & - & - & - \\
\hline
\end{tabular}

Only significant differences between distinct chromosomal imbalances (first line) and the possibles status of all other high-frequency alterations (gain/loss vs no changes) are shown $(P<0.05)$.

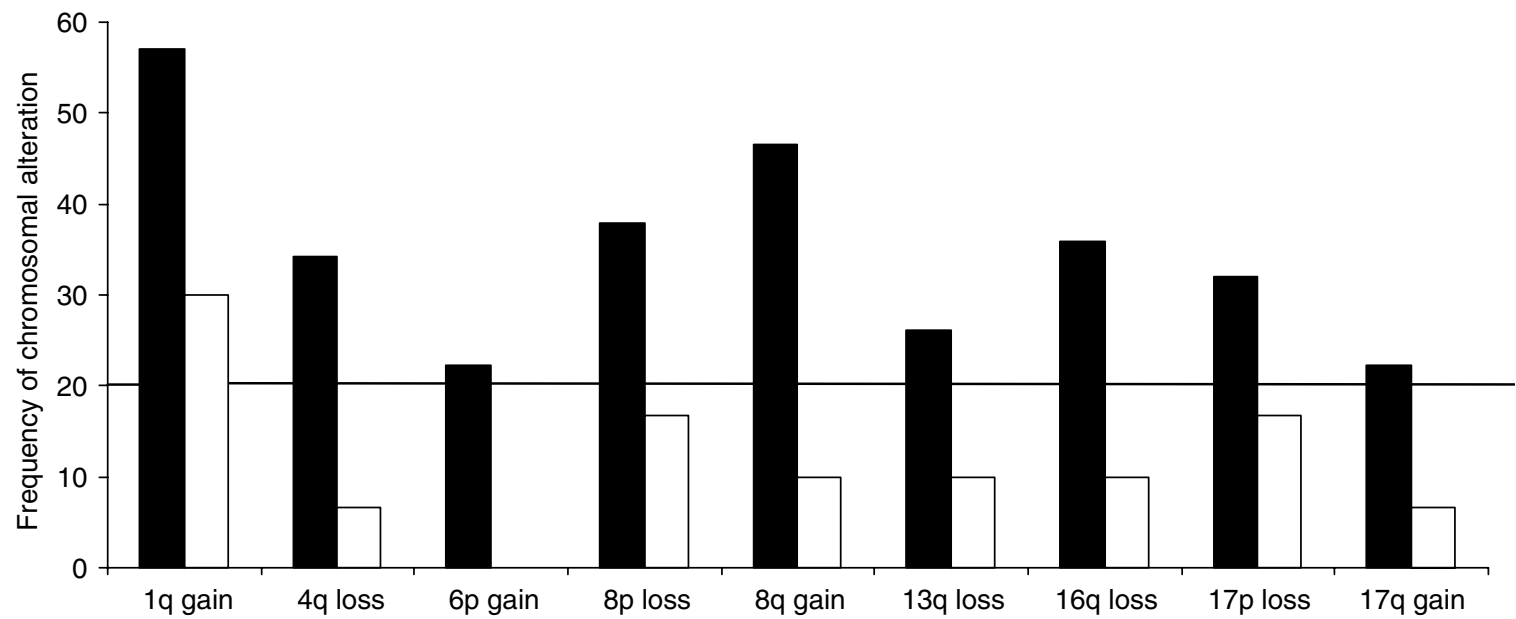

Figure 3 Direct comparison of chromosomal high-frequency alterations ( $\geqslant 20 \%)$ in HCCs (black bars) and related DNs (white bars).

they may predispose to chromosomal alterations. Thus, the status of 1q may distinguish between two different molecular pathways in hepatocarcinogenesis, of which cases with 1q gains are characterised by early-on acquired genomic imbalances ('mutator phenotype', Figure 4). This hypothesis is further supported by our finding that HCCs with 1q gains carry significantly more additional chromosomal alterations as compared to HCCs without $1 \mathrm{q}$ amplifications.
Taking these considerations into account, the following hypotheses can be formulated:

(a) Dysplastic nodules are premalignant precursor lesions that already carry fixed genomic alterations.

(b) Specific aetiologies, especially chronic HBV infection, may lead to characteristic host genomic alterations. Deletions on 


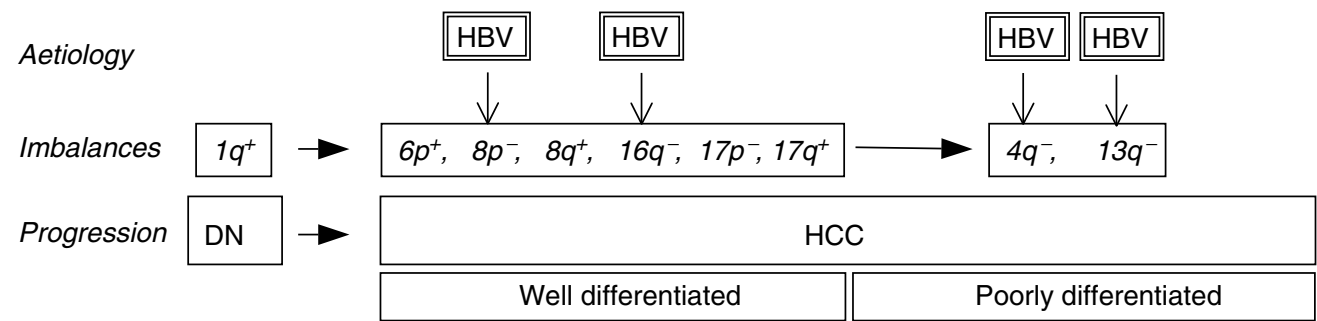

Figure 4 Schematic display of the CGH meta-analysis showing high-frequency chromosomal changes (imbalances) in association with aetiology and progression.

chromosome 4q, 13q, and $16 \mathrm{q}$ strongly correlate with HBV aetiology and tumour progression $(4 \mathrm{q}$ and $13 \mathrm{q})$, and may therefore contribute to the functional loss of tumour suppressors.

(c) Gains of $1 \mathrm{q}$ are the predominant early genomic alterations. They are aetiology-independent and may further predispose to other chromosomal imbalances ('mutator phenotype').

These hypotheses will have to be tested experimentally by several means. Firstly, the data basis in regard to DNs is still restricted and it is worthwhile to increase the number of CGH analyses of DNs. Secondly, the resolution of conventional CGH analysis to identify regions of interest is limited (approximately $3-10 \mathrm{Mbp}$ ). This gap may in part be closed by high-resolution techniques such as matrix-CGH (down to approximately $100 \mathrm{kbp}$

\section{REFERENCES}

Blanquet V, Garreau F, Chenivesse X, Brechot C, Turleau C (1988) Regional mapping to $4 \mathrm{q} 32.1$ by in situ hybridization of a DNA domain rearranged in human liver cancer. Hum Genet 80: 274-276

Breuhahn K, Vreden S, Haddad R, Beckebaum S, Stippel D, Flemming P, Nussbaum T, Caselmann WH, Haab BB, Schirmacher P (2004) Molecular profiling of human hepatocellular carcinoma defines mutually exclusive interferon regulation and insulin-like growth factor II overexpression. Cancer Res 64: 6058-6064

Buetow KH, Murray JC, Israel JL, London WT, Smith M, Kew M, Blanquet V, Brechot C, Redeker A, Govindarajah S (1989) Loss of heterozygosity suggests tumor suppressor gene responsible for primary hepatocellular carcinoma. Proc Natl Acad Sci USA 86: 8852 - 8856

Caselmann WH, Meyer M, Kekule AS, Lauer U, Hofschneider PH, Koshy R (1990) A trans-activator function is generated by integration of hepatitis B virus preS/S sequences in human hepatocellular carcinoma DNA. Proc Natl Acad Sci USA 87: 2970-2974

Cui J, Zhou X, Liu Y, Tang Z, Romeih M (2003) Wnt signaling in hepatocellular carcinoma: analysis of mutation and expression of betacatenin, T-cell factor-4 and glycogen synthase kinase 3-beta genes. J Gastroenterol Hepatol 18: 280-287

Edmondson HA, Steiner PE (1954) Primary carcinoma of the liver: a study of 100 cases among 48,900 necropsies. Cancer 7: $462-503$

El-Serag HB (2002) Hepatocellular carcinoma: an epidemiologic view. J Clin Gastroenterol 35: S72-S78

Feitelson MA (1998) Hepatitis B $\mathrm{x}$ antigen and p53 in the development of hepatocellular carcinoma. J Hepatobiliary Pancreat Surg 5: $367-374$

Kato N, Lan KH, Ono-Nita SK, Shiratori Y, Omata M (1997) Hepatitis C virus nonstructural region $5 \mathrm{~A}$ protein is a potent transcriptional activator. J Virol 71: 8856-8859

Kekule AS, Lauer U, Meyer M, Caselmann WH, Hofschneider PH, Koshy R (1990) The preS2/S region of integrated hepatitis B virus DNA encodes a transcriptional transactivator. Nature 343: $457-461$

Kern MA, Breuhahn K, Schirmacher P (2002a) Molecular pathogenesis of human hepatocellular carcinoma. Adv Cancer Res 86: 67-112

Kern MA, Schubert D, Sahi D, Schoneweiss MM, Moll I, Haugg AM, Dienes HP, Breuhahn K, Schirmacher P (2002b) Proapoptotic and antiproli-
(Wessendorf et al, 2002; Pestova et al, 2004). Identification and functional analyses of potential target genes may finally unravel the mechanisms that predispose to secondary chromosomal changes (e.g. 1q) or aetiology-specific alterations (e.g. 4q).

\section{ACKNOWLEDGEMENTS}

The study was supported by grants from the Dr Mildred ScheelStiftung für Krebsforschung, and the Deutsche Forschungsgemeinschaft to PS.

Supplementary Information accompanies the paper on British Journal of Cancer website (http://www.nature.com/bjc).

ferative potential of selective cyclooxygenase- 2 inhibitors in human live tumor cells. Hepatology 36: $885-894$

Koike K (1995) Hepatitis B virus HBx gene and hepatocarcinogenesis. Intervirology 38: $134-142$

Levine AJ (1997) p53, the cellular gatekeeper for growth and division. Cell 88: $323-331$

Luber B, Arnold N, Sturzl M, Hohne M, Schirmacher P, Lauer U, Wienberg J, Hofschneider PH, Kekule AS (1996) Hepatoma-derived integrated HBV DNA causes multi-stage transformation in vitro. Oncogene 12 $1597-1608$

Matsumura T, Makino R, Mitamura K (2001) Frequent down-regulation of E-cadherin by genetic and epigenetic changes in the malignant progression of hepatocellular carcinomas. Clin Cancer Res 7: 594-599

Moriya K, Fujie H, Shintani Y, Yotsuyanagi H, Tsutsumi T, Ishibashi K, Matsuura Y, Kimura S, Miyamura T, Koike K (1998) The core protein of hepatitis $\mathrm{C}$ virus induces hepatocellular carcinoma in transgenic mice. Nat Med 4: $1065-1067$

Nagaya T, Nakamura T, Tokino T, Tsurimoto T, Imai M, Mayumi T, Kamino K, Yamamura K, Matsubara K (1987) The mode of hepatitis B virus DNA integration in chromosomes of human hepatocellular carcinoma. Genes Dev 1: 773-782

Ozturk M (1999) Genetic aspects of hepatocellular carcinogenesis. Semin Liver Dis 19: 235-242

Pasquinelli C, Garreau F, Bougueleret L, Cariani E, Grzeschik KH, Thiers V, Croissant O, Hadchouel M, Tiollais P, Brechot C (1988) Rearrangement of a common cellular DNA domain on chromosome 4 in human primary liver tumors. J Virol 62: 629-632

Paterlini P, Brechot C (1991) The detection of hepatitis B virus (HBV) in HBsAG negative individuals with primary liver cancer. Dig Dis Sci 36: $1122-1129$

Pestova E, Wilber K, King W (2004) Microarray-based CGH in cancer. Methods Mol Med 97: 355-375

Prange W, Breuhahn K, Fischer F, Zilkens C, Pietsch T, Petmecky K, Eilers R, Dienes HP, Schirmacher P (2003) Beta-catenin accumulation in the progression of human hepatocarcinogenesis correlates with loss of E-cadherin and accumulation of p53, but not with expression of conventional WNT-1 target genes. J Pathol 201: 250-259 
Qin LF, Ng IO, Fan ST, Ng M (1998) p21/WAF1, p53 and PCNA expression and p53 mutation status in hepatocellular carcinoma. Int J Cancer 79: $424-428$

Weiss MM, Hermsen MA, Meijer GA, van Diest PJ (2002) Comparative genomic hybridization in cancer investigations. Methods Mol Biol 204: $369-378$

Wessendorf S, Fritz B, Wrobel G, Nessling M, Lampel S, Goettel D, Kuepper M, Joos S, Hopman T, Kokocinski F, Dohner H, Bentz M, Schwaenen C, Lichter P (2002) Automated screening for genomic imbalances using matrix-based comparative genomic hybridization. Lab Invest 82: $47-60$

Wollersheim M, Debelka U, Hofschneider PH (1988) A transactivating function encoded in the hepatitis $B$ virus $X$ gene is conserved in the integrated state. Oncogene 3: $545-552$

Zhang X, Xu HJ, Murakami Y, Sachse R, Yashima K, Hirohashi S, Hu SX, Benedict WF, Sekiya T (1994) Deletions of chromosome 13q, mutations in Retinoblastoma 1, and retinoblastoma protein state in human hepatocellular carcinoma. Cancer Res 54: 4177-4182 